\title{
Fluorescence Polarization Studies of Rat Intestinal
}

\section{Microvillus Membranes}

\author{
DAVID SCHACHTER and MEIR SHINITZKY \\ From the Department of Physiology, Columbia University, College of Physicians and Surgeons, \\ New York 10032 and the Department of Membrane Research, the Weizmann Institute of \\ Science, Rehovot, Israel
}

A B S T R A C T Rat intestinal microvillus membranes and lipid extracts prepared from them have been studied by fluorescence polarization with three lipidsoluble fluorophores: diphenylhexatriene, retinol, and anthroyl-stearate. The degree of fluorescence polarization of diphenylhexatriene, which provides an index of the "microviscosity" of the lipid regions of the membrane, is exceptionally high in microvillus membranes, the highest yet reported in normal biological membranes. Both the membrane proteins and lipids were found to contribute to the high values. With each of the three probes the polarization values are higher in ileal microvillus membranes as compared to membranes from proximal intestinal segments. Temperature-dependence studies of the fluorescence polarization of diphenylhexatriene and anthroylstearate demonstrate a phase transition in microvillus membranes and in liposomes prepared from their lipid extracts at approximately $26 \pm 2^{\circ} \mathrm{C}$. Ambient $\mathrm{pH}$ influe.ices markedly the diphenylhexatriene fluorescence polarization in microvillus membranes but has little effect on that of human erythrocyte ghost membranes. The "microviscosity" of jejunal microvillus membranes is maximal at $\mathrm{pH} 6.5-7.0$ and decreases as much as $50 \%$ at $\mathrm{pH} 3.0$, an effect which depends largely upon the membrane proteins. Addition of calcium ions to suspensions of microvillus membranes increases the fluorescence polarization of retinol and anthroyl-stearate, but not that of diphenylhexatriene. This confirms the localization of the last compound to the hydrophobic interior of the membrane, relatively distant from the hydrophilic head groups of the polar lipids. Microvillus membrane proteins solubilized with Triton $\mathrm{X}-100$ give relatively high fluorescence polarization and intensity values

Dr. Schachter is the recipient of a Faculty Scholar Award from the Josiah Macy, Jr. Foundation.

Received for publication 10 August 1976 and in revised form 19 November 1976. with retinol, suggesting the presence of binding proteins which could play a role in the normal absorptive mechanism for the vitamin.

\section{INTRODUCTION}

In recent years fluorescence polarization methods have been applied increasingly to the study of biological membranes (1-8). The particular usefulness of these methods stems from the fact that the polarization of the fluorescence of a molecule depends upon its rate of rotation (9). Hence, changes in rotation rate due to interactions of the probe with other species in the environment are readily observed and quantified. For example, the binding of a fluorophore to a biological macromolecule or membrane can be monitored by an increase in the polarization of fluorescence (9). Similarly, since the rotation rate depends on the resistance offered by the microenvironment to the motion of the probe, fluorescence polarization provides an estimate of the environmental resistance which is interpretable as an apparent "microviscosity" (1-5, $7,10-13)$.

Studies of the last type have focussed recently on the degree of fluidity of the nonpolar regions of biological membranes. The estimations have been expedited greatly by the introduction of a highly efficient hydrocarbon fluorophore, 1,6-diphenyl-1,3,5-hexatriene $(\mathrm{DPH})^{1}$, which is localized in the hydrophobic regions of biological membranes $(1,12,14)$. Fluorescence polarization measurements demonstrate that the resistance to rotation encountered by the probe varies in membranes of different cell types $(1-3,7,8)$.

\footnotetext{
${ }^{1}$ Abbreviations used in this paper: DPH, 1,6-diphenyl1,3,5-hexatriene; F, fluorescence intensity; PBS, phosphatebuffered saline; $r$, fluorescence anisotropy; $r_{o}$, maximal limiting anisotropy; T, absolute temperature; THF, tetrahydrofuran; $\Delta \mathrm{E}$, flow activation energy; $\bar{\eta}$, apparent microviscosity; $\rho$, rotational relaxation time of the fluorophore; $\tau$, lifetime of the excited state of the fluorophore.
} 
In leukemic human and mouse lymphocytes, for example, the polarization of the DPH fluorescence is less than that in the corresponding normal lymphocytes, indicating that the resistance to rotation, and hence the "microviscosity," is decreased in the leukemic cells $(1,3)$.

The present studies were undertaken to characterize the fluidity of the nonpolar regions of isolated rat intestinal microvillus membranes by estimations of the fluorescence polarization of DPH and other lipid probes. These membranes are of considerable physiological and clinical interest because they are highly organized to perform a variety of essential digestive and transport functions. The results to be described demonstrate a number of characteristic features of the microvillus membranes, including a relatively high resistance to rotation of the lipid probes (i.e., high "microviscosity"), a temperature-dependent phase transition and a dependence of the membrane "microviscosity" on ambient hydrogen ion concentration.

\section{METHODS}

Animals. Experiments were performed both at the Weizmann Institute and at Columbia University. Despite differences in the strain of rats employed and the fluorescence polarization instrumentation (see below), the results obtained in both institutions were very similar and have been pooled throughout this report. At the Weizmann Institute CR/RAR strain, albino, female rats were used and at Columbia University the rats were albino males of the Sherman strain. In all studies rats weighing 200-300 g were fasted for $18 \mathrm{~h}$ with water ad libitum before removal of the small intestine.

Instruments. The fluorescence polarization instrument employed at the Weizmann Institute was constructed there and has been described (15). The Elscint model MV-1 Microviscosimeter was also used. The instrument at Columbia University was purchased from SLM Instruments, Champaign, Ill.

Membrane preparations. In a typical experiment four or five rats were stunned rapidly by a blow to the head and killed by exsanguination. The entire small intestine was resected and segments of duodenum (proximal $12 \mathrm{~cm}$ ), jejunum (middle $25 \mathrm{~cm}$ ), and ileum (distal $15 \mathrm{~cm}$ ) opened and washed thoroughly in ice-cold $145 \mathrm{mM} \mathrm{NaCl}-4 \mathrm{mM}$ $\mathrm{KCl}$. The mucosa of each segment was scraped off with a glass slide and the duodenal, jejunal, and ileal scrapings pooled separately and weighed. Thereafter, microvillus membranes were prepared by one of two methods. In the first procedure whole brush borders were obtained by homogenizing the mucosa in hypotonic sodium EDTA of pH 7.4 as previously described $(16,17)$. Thereafter, the brush borders were suspended in $100 \mathrm{mM}$ mannitol containing 1 $\mathrm{mM}$ Hepes-Tris of $\mathrm{pH}$ 7.5. Microvillus membranes were then prepared as described by Hopfer et al. (18) by highspeed homogenization in a Potter homogenizer (Potter Instrument Co., Inc., Plainview, N. Y.) fitted with a Teflon pestle and driven by an electric drill, followed by differential centrifugation. In the second procedure the mucosal scrapings were homogenized in a Waring blendor (Waring Products Div., New Hartford, Conn.), treated with $10 \mathrm{mM} \mathrm{CaCl}_{2}$, and a brush border particulate fraction obtained by differential centrifugation as described by Schmitz et al. (19). The brush border fraction was then homogenized at high speed according to the method of Hopfer et al. (18) and the microvillus membranes separated by differential centrifugation. The final membrane pellets were suspended in either phosphate-buffered saline $(20)$ or $13 \mathrm{mM}$ Tris buffer of $\mathrm{pH} 7.4$ and tested immediately or within $24 \mathrm{~h}$. For longer periods the membranes were stored frozen at $-15^{\circ} \mathrm{C}$, which preserves better the original fluorescence polarization and disaccharidase values. The purity and comparability of the various preparations was assessed by estimations of maltase specific activity (17). Membranes prepared from all three segments of the intestine and by each of the methods of preparation were consistently purified 15- to 18-fold as compared to the original homogenates. Moreover, both methods of microvillus membrane preparation gave similar results in studies with the fluorescent probes and the data have been combined below.

Human erythrocyte ghost membranes were prepared by hypotonic lysis by a modification of the method of Dodge et al. (21). Erythrocytes were obtained by centrifugation of recently outdated blood bank blood and washed twice with 10 vol of isotonic $\mathrm{NaCl}$ containing $30 \mathrm{mM}$ sodium phosphate of $\mathrm{pH}$ 7.4. The packed cells were then lysed in $150 \mathrm{vol}$ of $8 \mathrm{mM}$ sodium phosphate of $\mathrm{pH} 7.4$ and the ghost membranes pelleted by centrifugation at $20,000 \mathrm{~g}$ for $40 \mathrm{~min}$ in a Sorvall centrifuge (Ivan Sorvall, Inc., Norwalk, Conn.) at $5^{\circ} \mathrm{C}$. The pellets were washed once with $30 \mathrm{vol}$ of the $8-\mathrm{mM}$ phosphate solution to yield a faintly pink suspension, which was stored at $5^{\circ} \mathrm{C}$ and studied within $48 \mathrm{~h}$ of the time of preparation.

Fluorescence studies. Three lipid-soluble fluorescent probes were used: DPH (Aldrich Chemical Co., Inc., Milwaukee, Wis.), all trans-retinol (Sigma Chemical Co., St. Louis, Mo.), and DL-12-(9-anthroyl)stearic acid (Sigma Chemical Co.). For the DPH studies a stock solution of $2-\mathrm{mM}$ probe in tetrahydrofuran (THF) was prepared and stored protected from light at room temperature. Aqueous suspensions of DPH were prepared freshly each day as previously described (1). A small volume of the DPH solution in THF was injected with rapid stirring into $1,000 \mathrm{vol}$ of phosphatebuffered saline (PBS) or other buffer at room temperature. The suspension was stirred for at least $2 \mathrm{~h}$ after which little or no odor of THF was detected and the suspension showed negligible fluorescence. In a typical experiment microvillus membranes equivalent to $100-200 \mu \mathrm{g}$ protein (22) were incubated in $2 \mathrm{ml}$ of PBS containing $1 \mu \mathrm{M}$ DPH suspension for $2-4 \mathrm{~h}$ at $37^{\circ} \mathrm{C}$. Thereafter, estimations of the fluorescence polarization and fluorescence intensity were made with an exciting wavelength of $365 \mathrm{~nm}(\mathrm{Hg}$ line) and passage of the emitted light through $1-\mathrm{cm}$ cut-off filters of $2 \mathrm{~m} \mathrm{NaNO}$. Control samples of DPH suspension alone and of membranes alone were examined in each experiment, but these readings could be neglected since they contributed less than $3 \%$ to the fluorescence of the complete system. The fluorescence intensity, F, was calculated as $I_{\|}+2 I_{\perp}$, where $I_{\|}$and $I_{\perp}$ are the fluorescence intensities oriented, respectively, parallel and perpendicular to the direction of polarization of the exciting light (1) Fluorescence intensity was expressed in arbitrary units. The polarization of fluorescence was expressed as the fluorescence anisotrophy, $r$, where $r=\left(I_{\|}-I_{\perp}\right) /\left(I_{\|}+21_{\perp}\right)$, and as the parameter $\left[\left(r_{o} / r\right)-1\right]^{-1}$. One form of the Perrin equation, on which the fluorescence polarization determinations were based, is:

$$
r_{0} / r=1+3 \tau / \rho
$$

where $\tau$ is the lifetime of the excited state of the fluorophore and $\rho$ is its rotational relaxation time. Hence at constant $\tau$ 
the parameter $\left[\left(r_{o} / r\right)-1\right]^{-1}$ is directly proportional to the rotational relaxation time and provides a quantitative index of the resistance of the environment to the rotational motion (3). The greater the value of $\left[\left(r_{d} / r\right)-1\right]^{-1}$ the higher is the apparent "microviscosity" of the environment. The term $r_{o}$ is the maximal limiting anisotropy, which for DPH was observed to have an experimental value of 0.362 (12), reasonably close to the theoretical upper limit of 0.40 . The fluorescence anisotropy, $r$, was also used to calculate the apparent microviscosity, $\bar{\eta}$, in absolute units of poise, using an indirect method for determining $\tau(1,12)$.

For studies of vitamin A, a fresh solution of $0.4 \mathrm{mM}$ all transretinol in absolute ethanol was prepared and $5 \mu \mathrm{l}$ was added with rapid mixing to $2 \mathrm{ml}$ of PBS containing microvillus membranes equivalent to $50-100 \mu \mathrm{g}$ protein, as previously described (23). After $15-20 \mathrm{~s}$ the fluorescence intensity and polarization was determined as described for $\mathrm{DPH}$, except that the wavelength of the exciting light was $334 \mathrm{~nm}$ ( $\mathrm{Hg}$ line). The fluorescence of each membrane sample minus retinol and that of retinol added to buffer alone were also determined and subtracted as corrections, never more than $30 \%$ of the total value. The maximal limiting anisotropy, $r_{0}$, for retinol has been estimated as 0.367 in propylene glycol at $-50^{\circ} \mathrm{C}(23)$.

For experiments with anthroyl-stearate, a stock solution of $0.25 \mathrm{mM}$ in $80 \%$ ethanol ( $\mathrm{vol} / \mathrm{vol}$ ) containing $10 \mathrm{mM}$ Hepes-Tris of $\mathrm{pH} 7.5$ was prepared and stored at $-15^{\circ} \mathrm{C}$. In fluorescence experiments $5 \mu$ l of the stock solution was added with rapid mixing to $2 \mathrm{ml}$ of PBS containing microvillus membranes equivalent to $50-100 \mu \mathrm{g}$ protein. After incubation for $15 \mathrm{~min}$ at room temperature the fluorescence polarization was determined as described for DPH. Appropriate controls containing either membranes alone or the probe alone were examined in each experiment and the fluorescence values observed, less than $15 \%$ of the total value, subtracted as corrections. An $r_{o}$ value of 0.285 was observed for anthroyl-stearate in propylene glycol at $-50^{\circ} \mathrm{C}$ and this was used in the calculations.

Lipid extracts and liposomes. Total lipids were extracted from intestinal microvillus and human erythrocyte membranes by the method of Folch et al. (24). The relative proportions of lipid and protein, respectively, observed in three separate preparations of rat jejunal microvillus membranes prepared by the $\mathrm{CaCl}_{2}$ method were $36.8 \%$ (range $31.8-38.9 \%$ ) and $63.2 \%$ (range 61.1-68.2\%), in agreement with prior data (25). Corresponding values obtained with a preparation of human erythrocyte membranes were $44.9 \%$ lipid and $55.1 \%$ protein, also in agreement with published values (26).

To prepare liposome suspensions the dried, extracted lipid was suspended in PBS to a final concentration of approximately $0.3 \mathrm{mg} / \mathrm{ml}$ and the mixture was sonicated for 10 min, under $\mathrm{N}_{2}$, at $5^{\circ} \mathrm{C}$, as previously described (3). Thereafter, the suspensions were centrifuged for $10 \mathrm{~min}$ at $20,000 \mathrm{~g}$ in a Sorvall centrifuge at $5^{\circ} \mathrm{C}$. The supernatant liposome suspensions were tested with the fluorescent probes as described for membranes above. In the final reaction mixtures the liposome suspensions were diluted two- to fourfold and fluorescence readings were obtained as described above.

Dried lipid extracts were also fractionated and assayed quantitatively for individual lipids by thin-layer chromatography according to the method of Yavin et al. (27).

Solubilized membrane proteins. Preparations of solubilized membrane proteins were made by extraction with Triton X-100 (Rohm \& Haas Co., Philadelphia, Pa.) followed by removal of the detergent. A suspension of membranes equivalent to $2-6 \mathrm{mg}$ protein was added to $10 \mathrm{vol}$ of $1.5 \%$ Triton X-100 in $10 \mathrm{mM}$ Tris buffer of $\mathrm{pH} 7.4$ and the mixture homogenized for $2 \mathrm{~min}$ in a Potter homogenizer at $5^{\circ} \mathrm{C}$. The mixture was then centrifuged at $104,000 \mathrm{~g}$, for $90 \mathrm{~min}$, at $5^{\circ} \mathrm{C}$ in a Spinco model L2 ultracentrifuge (Beckman Instruments, Inc., Spinco Div., Palo Alto, Calif.). The supernatant solution was mixed with an equal volume of washed Bio-Beads (Bio-Rad Laboratories, Richmond, Calif.) and shaken for $2-3 \mathrm{~h}$ at $5^{\circ} \mathrm{C}$. Aliquots of the solution were tested for residual Triton by estimating the optical density at $275 \mathrm{~nm}$ in a Beckman model DU spectrophotometer (Beckman Instruments, Inc., Fullerton, Calif.). After one or two treatments with the Bio-Beads, Triton was no longer detectable. The beads were removed by centrifugation and the supernatant solutions were stored frozen at $-15^{\circ} \mathrm{C}$. The final preparations from rat jejunal and human erythrocyte membranes contained approximately $10 \%$ of the total membrane proteins. Assays of lipid phosphorus (28) showed that the intestinal and erythrocyte preparations, respectively, contained 31 and $66 \%$ of the original lipid phosphorus per milligram protein as compared to the original membranes.

Temperature studies. To examine the effects of temperature $(\mathrm{T})$, membranes or liposomes loaded with DPH were warmed to $40^{\circ} \mathrm{C}$ and the fluorescence polarization determined every $1-2^{\circ} \mathrm{C}$ as the preparations were cooled slowly to $0^{\circ} \mathrm{C}$. The logarithm of the parameter $\left[\left(r_{0} / r\right)-1\right]^{-1}$ was plotted against the reciprocal of the absolute temperature. Prior reports $(3,12-14)$ indicate that a change in slope of such a plot can be used to detect a phase transition. In addition, the "microviscosity", $\bar{\eta}$, was calculated from the anisotropy values observed and from indirect estimates of the lifetime of the excited state, as previously described $(1,12)$. The change of $\bar{\eta}$ with temperature can be described in a simple exponential form:

$$
\bar{\eta}=\mathrm{Ae}^{\Delta \mathrm{E} / \mathrm{RT}},
$$

where $\Delta \mathrm{E}$ is a "flow activation energy" determinable from the slope of the plot of $\log \bar{\eta}$ vs. 1/T (10) and A is a constant whose significance has been discussed (3).

Effects of $p H$. To study the effects of the ambient $\mathrm{pH}$, membranes or liposomes were loaded with DPH in $0.15 \mathrm{M}$ $\mathrm{NaCl}$ in the absence of buffer. The $\mathrm{pH}$ of the suspension was monitored directly with a Corning model $\mathrm{A} \mathrm{pH}$ meter and glass electrode (Corning Scientific Instruments, Medfield, Mass.), and changes in $\mathrm{pH}$ were brought about by addition of $1-\mu \mathrm{l}$ aliquots of $10 \mathrm{mM} \mathrm{NaOH}$ or $\mathrm{HCl}$. Fluorescence polarization was determined at each $\mathrm{pH}$ value as described above.

\section{RESULTS}

Comparison of crude homogenates and microvillus membranes. Crude mucosal homogenates, brushborder particulates, and microvillus membranes prepared by the $\mathrm{CaCl}_{2}$ method from duodenal, jejunal, and ileal segments were each tested with DPH, retinol, and anthroyl-stearate, and the fluorescence polarization values are shown in Fig. 1. For all three probes and segments the $\left[\left(r_{o} / r\right)-1\right]^{-1}$ values were greater in the microvillus membranes and brush-border particulates as compared to the corresponding homogenates $(P<0.001)$; and in all but one instance (anthroyl-stearate in duodenal preparations) the values for microvillus membranes exceeded those of the corresponding brush-border particulates $(P$ 
$<0.002)$. The greatest difference between homogenate and membrane was observed with DPH in the jejunal preparations, where the value for the microvillus membranes was over 2.6-fold that for the homogenate. For each probe the total fluorescence intensity, F, was also greater in the membranes as compared to the homogenates $(P<0.001)$. The values of $\mathrm{F}$ (arbitrary units per milligram protein) observed with DPH in the jejunal preparations, for example, were 21.3, 62.8, and 94.1 , respectively, for the homogenate, brushborder particulate, and microvillus membranes. This pattern is noteworthy because the relatively high polarization values observed for microvillus membranes could in principle result from a shortened lifetime of the excited state of the probe (see Eq. 1). However, a shortened lifetime would decrease $\mathrm{F}$, whereas an increase was actually observed.

Further evidence that the brush border shows a much higher polarization of the fluorescence of DPH than the whole mucosal cell was obtained with a fluorescence polarization microscope (Elscint, Ltd., Haifa, Israel). In this instrument the excitation beam can be focussed on a single cell or isolated brush border and the polarization estimated. Rat jejunal mucosal cell suspensions and suspensions of isolated
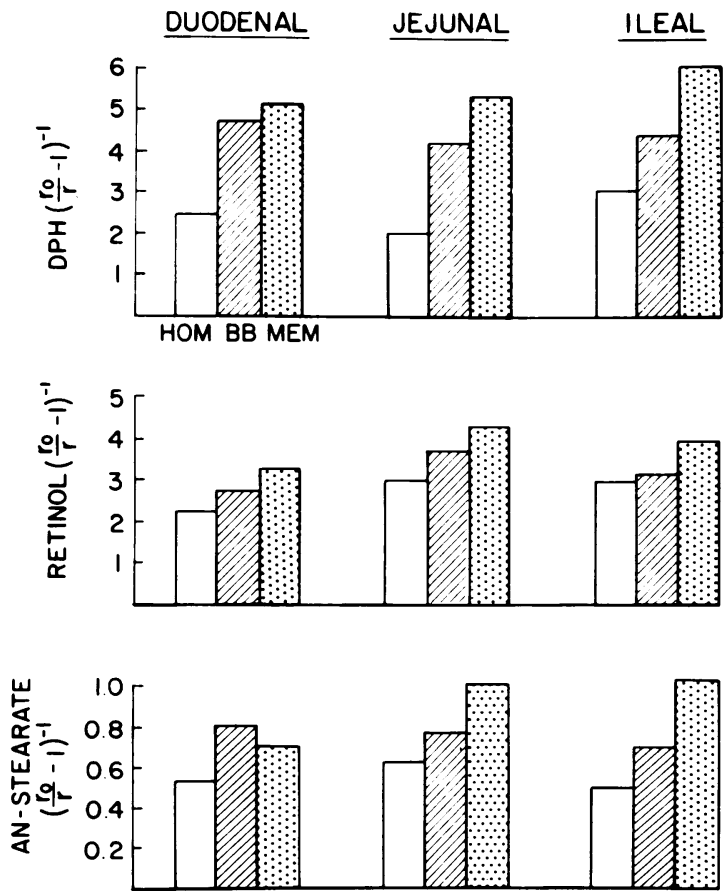

FIGURE 1 Fluorescence polarization of diphenylhexatriene, retinol, and anthroyl (AN)-stearate in unfractionated mucosal homogenates (HOM, open bars), brush-border suspensions (BB, crosshatched bars), and microvillus membranes (MEM, stippled bars). Values are for a preparation from five rats; brush borders and membranes were prepared by the EDTA method, as described in Methods.
TABLE I

Fluorescence Polarization of Diphenylhexatriene in Microvillus Membranes of Various Intestinal Segments

\begin{tabular}{lccc}
\hline \multirow{2}{*}{ Segment } & \multicolumn{2}{c}{ Fluorescence polarization } & Microviscosity, \\
\cline { 2 - 3 } & $r$ & {$\left[\left(r_{d} / r\right)-1\right]^{-1}$} & $\bar{\eta}$ \\
\hline & & & poise \\
Duodenum & $0.282 \pm 0.006$ & $3.68 \pm 0.35$ & $12.4 \pm 1.2$ \\
Jejunum & $0.282 \pm 0.006$ & $3.74 \pm 0.41$ & $12.5 \pm 1.3$ \\
Ileum & $0.293 \pm 0.003$ & $4.39 \pm 0.33$ & $14.7 \pm 1.1$ \\
\hline
\end{tabular}

All values are means $\pm \mathrm{SE}$ for eight separate groups of rats. On paired analyses the duodenal-ileal anisotropy difference has $\mathrm{SE}=0.0025, P<0.005$; the corresponding jejunal-ileal difference has $\mathrm{SE}=0.0027, P<0.005$. All values are for $25^{\circ} \mathrm{C}$. Microviscosity, $\bar{\eta}$, was calculated as previously described $(3,12)$.

brush borders from these cells were loaded with DPH (Methods) and examined individually in the microscope. Values of $\left[\left(r_{o} / r\right)-1\right]^{-1}$ for the whole cells and brush borders, respectively, were $0.44 \pm 0.01$ and $0.96 \pm 0.03($ mean $\pm \mathrm{SE}, n=23, P<0.001)$.

Comparison of segments. Regional differentiation of the small intestinal mucosa for specific functions is well established, and we have reported previously (23) that microvillus membranes from ileal segments show higher polarization values with retinol than do more proximal membranes. Table 1 summarizes the results of eight experiments in each of which duodenal, jejunal, and ileal membranes were tested with DPH. Anisotropy values for the duodenal and jejunal membranes were similar, whereas the ileal values were significantly higher $(P<0.005)$. The mean value calculated for $\bar{\eta}$, the "microviscosity", was approximately $18 \%$ higher for ileal as compared to duodenal and jejunal membranes. It is further noteworthy that the absolute $\bar{\eta}$ values $\left(25^{\circ} \mathrm{C}\right)$ for all the microvillus membranes, $12-15$ poise, are considerably greater than those reported for a number of mammalian membranes (3), among which human erythrocyte ghost membranes showed the highest value, 6.3 poise.

The DPH fluorescence intensity, F, observed for the duodenal, jejunal, and ileal membranes, respectively, in the foregoing experiments was $81.5 \pm 11.3$, $63.1 \pm 8.3$, and $44.4 \pm 6.4$ (mean $\pm \mathrm{SE}$; arbitrary units per milligram membrane protein). The duodenal-ileal difference is significant (paired analysis, $\mathrm{SE}=8.4$, $P<0.005)$ whereas the jejunal-ileal difference borders on significance $(\mathrm{SE}=8.5,0.05<P<0.1)$. These differences in $F$ result from differences in the quantity of DPH taken up by the membranes rather than from changes in lifetime of the excited state of the probe. Differences in uptake were demonstrated directly by the following experiment. Duodenal, 
TABLE II

Fluorescence Polarization of Anthroyl-Stearate in Microvillus Membranes of Various Intestinal Segments

\begin{tabular}{lcc}
\hline \multirow{2}{*}{ Scgment } & \multicolumn{2}{c}{ Fluorescence polarization } \\
\cline { 2 - 3 } & $r$ & {$\left[\left(r_{,}, r\right)-1\right]^{-1}$} \\
\hline Duodenum & $0.123 \pm 0.006$ & $0.78 \pm 0.07$ \\
Jejunum & $0.133 \pm 0.009$ & $0.90 \pm 0.10$ \\
Ileum & $0.137 \pm 0.008$ & $0.97 \pm 0.10$ \\
\hline
\end{tabular}

Values are means $\pm S E$ for three groups of rats. On paired analyses the anisotropy differences between ileal membranes and those from the other segments have $\mathrm{SE}=0.0036, P<0.05$. All determinations were at $25^{\circ} \mathrm{C}$.

jejunal, and ileal membranes were prepared and loaded with the probe as described (Methods), except that the DPH contained sufficient $\left[{ }^{3} \mathrm{H}\right] \mathrm{DPH}$ to yield a specific radioactivity of $2 \times 10^{10} \mathrm{cpm} / \mathrm{mmol}$. The membranes were then washed twice with $40 \mathrm{vol}$ of PBS and aliquots were taken for determination of radioactivity by liquid scintillation spectrometry (29). The uptake of $\left[{ }^{3} \mathrm{H}\right] \mathrm{DPH}$ by the duodenal, jejunal and ileal membranes, respectively, was $6,580,5,030$, and $3,460 \mathrm{cpm} / \mathrm{mg}$ membrane protein. These quantities correspond to relative uptake values of $1.00 / 0.76 / 0.53$ and parallel closely the corresponding relative values for F, 1.00/0.77/0.54.

Experiments with three groups of rats were performed to determine the fluorescence polarization of anthroyl-stearate in microvillus membranes from each of the three intestinal segments. The results shown in Table II demonstrate that the molecular anisotropy was significantly higher in ileal membranes as compared to more proximal membranes $(P<0.05)$. The mean $\left[\left(r_{0} / r\right)-1\right]^{-1}$ value of the ileal membranes was $24 \%$ greater than that of the duodenal membranes.

Comparison of whole membranes and membrane components. The relative contribution of membrane lipid as compared to protein to the fluorescence polarization of DPH and retinol was studied with rat jejunal microvillus membranes and human erythrocyte membranes. Three preparations of each membrane type were used as starting materials from which lipid extracts, liposomes, and Triton-solubilized proteins were prepared (Methods). The intact membranes and membrane components were then tested with each probe and the fluorescence polarization results are shown in Table III. In the microvillus preparations the mean $\left[\left(r_{0} / r\right)-1\right]^{-1}$ value for DPH was $72.8 \%$ higher in the intact membranes than in the liposomes $(P<0.01)$, and a still greater increment, $131.6 \%$, was observed for the corresponding retinol values $(P$ $<0.02$ ). Thus, the presence of the membrane proteins is essential for the relatively high polarization values of the microvillus membranes. This conclusion is further supported by a comparison of the DPH values in microvillus and erythrocyte membranes. The mean $\left[\left(r_{o} / r\right)-1\right]^{-1}$ values $\left(25^{\circ} \mathrm{C}\right)$ for the intact jejunal and erythrocyte membranes, respectively, were 5.46 and $2.93(P<0.02)$, confirming the results described in the preceding section. However, the corresponding values for the liposomes prepared from these membranes were 3.16 and 3.02 (NS). Thus, the characteristic difference in polarization between the microvillus and erythrocyte membranes is dependent

TABLE III

Fluorescence Polarization in Whole Membranes and in Membrane Components

\begin{tabular}{|c|c|c|c|}
\hline Membrane type & Preparation & $\begin{array}{c}\text { Diphenylhexatriene } \\
{\left[\left(r_{d} / r\right)-1\right]^{-1}}\end{array}$ & $\begin{array}{c}\text { Retinol } \\
{\left[\left(r_{d} / r\right)-1\right]^{-1}}\end{array}$ \\
\hline $\begin{array}{l}\text { Rat jejunal microvillus } \\
\text { membrane }\end{array}$ & $\begin{array}{l}\text { Intact membranes } \\
\text { Liposomes } \\
\text { Triton-solubilized } \\
\text { proteins }\end{array}$ & $\begin{array}{l}5.46 \pm 0.56 \\
3.16 \pm 0.12 \\
3.02 \pm 0.06\end{array}$ & $\begin{array}{l}3.59 \pm 0.53 \\
1.55 \pm 0.08 \\
5.78 \pm 0.20\end{array}$ \\
\hline $\begin{array}{l}\text { Human erythrocyte } \\
\text { membrane }\end{array}$ & $\begin{array}{l}\text { Intact membranes } \\
\text { Liposomes } \\
\text { Triton-solubilized } \\
\quad \text { proteins }\end{array}$ & $\begin{array}{l}2.93 \pm 0.09 \\
3.02 \pm 0.04 \\
2.96 \pm 0.15\end{array}$ & $\begin{array}{l}2.50 \pm 0.51 \\
1.66 \pm 0.62 \\
2.91 \pm 0.72\end{array}$ \\
\hline
\end{tabular}

Values are means $\pm \mathrm{SE}$ for three groups of rats or blood samples. Determinations of fluorescence polarization were at $25^{\circ} \mathrm{C}$. On $t$ test the significant differences were the following: for DPH, microvillus membranes vs. liposomes ( $\mathrm{SEM}=0.51, P<0.01$ ), microvillus membranes vs. erythrocyte membranes $(\mathrm{SEM}=0.62, P<0.02)$; for retinol, microvillus membranes vs. liposomes $(\mathrm{SEM}=0.51, P<0.02)$, microvillus membranes vs. solubilized proteins $(\mathrm{SEM}=0.51, P<0.01)$, microvillus solubilized proteins vs. liposomes $(\mathrm{SEM}=0.18, P<0.001)$, and microvillus solubilized proteins vs. erythrocyte solubilized proteins $(\mathrm{SEM}=0.49, P<0.01)$. 
upon the presence of the membrane proteins. The retinol polarization values of the two membrane types follow a pattern similar to that for DPH (Table III).

The Triton-solubilized proteins were studied to obtain direct evidence concerning the membrane protein component. It bears emphasis, however, that the preparations contained only $10 \%$ of the total membrane proteins. The DPH $\left[\left(r_{o} / r\right)-1\right]^{-1}$ values of the protein preparations were essentially identical with those of the liposomes (Table III) in each membrane type. In contrast, the mean retinol value observed for the microvillus protein preparations, 5.78, was considerably greater than that of the liposomes, 1.55 $(P<0.001)$, or that of the intact membranes, 3.58 $(P<0.01)$. A less pronounced but similar pattern was observed for the retinol values in erythrocyte preparations, but the differences are not statistically significant. The results indicate that the influence of the microvillus membrane proteins on the fluorescence polarization of DPH could be indirect, i.e., via restriction of lipid mobility due to protein-lipid interactions. This mechanism seems likely from the known properties of DPH (12-14) and from additional observations described below, although direct binding of DPH by membrane proteins is not entirely excluded. The results with retinol indicate that at least some of the probe is bound to microvillus membrane proteins. The Triton-solubilization procedure appears to concentrate some of the binding proteins, so that the fluorescence polarization of retinol is relatively high in these preparations. Further evidence is necessary to establish the specific-

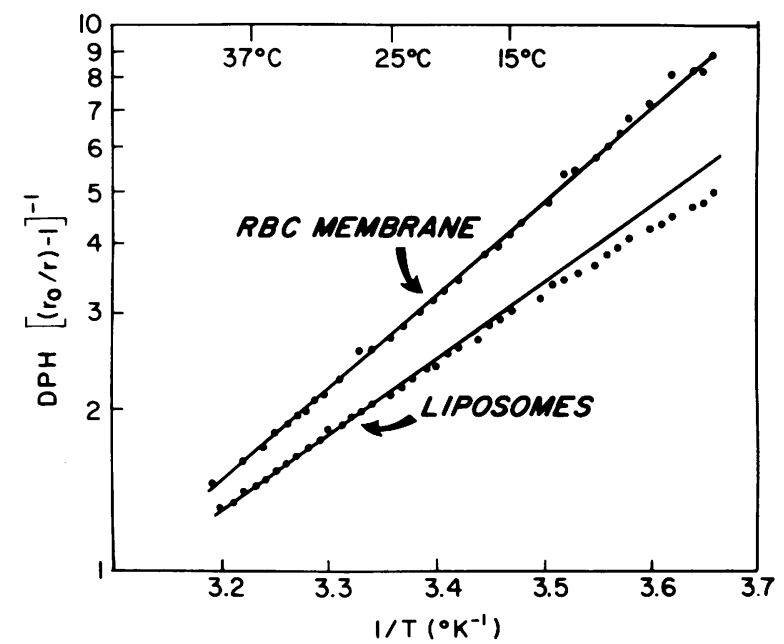

FIGURE 2 Temperature dependence of the fluorescence polarization of diphenylhexatriene in human erythrocyte (RBC) ghost membranes and in liposomes prepared from ghost membrane lipid. The horizontal axis is the reciprocal of the absolute temperature, with $\mathrm{T}=$ absolute temperature $\times 10^{-3}$.

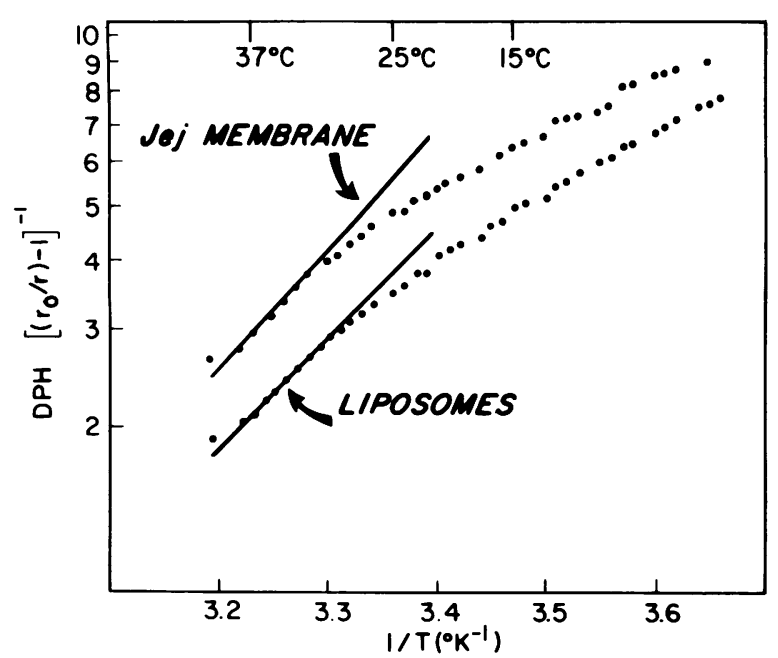

Figure 3 Temperature dependence of the fluorescence polarization of diphenylhexatriene in rat jejunal (Jej) microvillus membranes and in liposomes prepared from the membrane lipid. Horizontal axis is labeled as in Fig. 2.

ity of such binding, but it is noteworthy that the $\left[\left(r_{o} / r\right)-1\right]^{-1}$ value of the intestinal microvillus protein preparation, 5.78, considerably exceeds that of the corresponding erythrocyte membrane preparation, 2.91 $(P<0.01)$.

Binding of retinol to the plasma retinol-binding protein increases considerably the total fluorescence, $\mathrm{F}$, of the probe $(30,31)$. It is noteworthy, therefore, that in the preceding experiments retinol $F$, expressed in arbitrary units per milligram protein, was 1.8 times greater in the solubilized protein preparations than in the intact microvillus membranes. The corresponding increment for DPH was only 1.3-fold.

Temperature studies. Prior publications $(1,3,12$ 14) have demonstrated that plots of the log DPH $\left[\left(r_{d} / r\right)-1\right]^{-1}$ or of $\log \bar{\eta}$ against the reciprocal of the absolute temperature yield useful information concerning phase transitions and dynamic parameters of the microenvironment of the probe. Accordingly, membranes and liposomes were loaded with DPH and studied over the temperature range $40-0^{\circ} \mathrm{C}$ (Methods).

Fig. 2 illustrates a typical study with human erythrocyte membranes and the liposomes prepared from them. Values for the membranes fall along a single line, indicative of a monophasic system, in accord with prior observations of erythrocyte and certain other mammalian membranes (1-3). The liposomes show a single slope to about $15^{\circ} \mathrm{C}$, with a small decrease in slope at the lower temperatures. In contrast to the erythrocyte preparations, intestinal microvillus membranes (8 preparations), whole brush borders (12 preparations), and liposomes prepared from them (7 preparations) each showed a distinct decrease in

Dynamics of Microvillus Membranes 


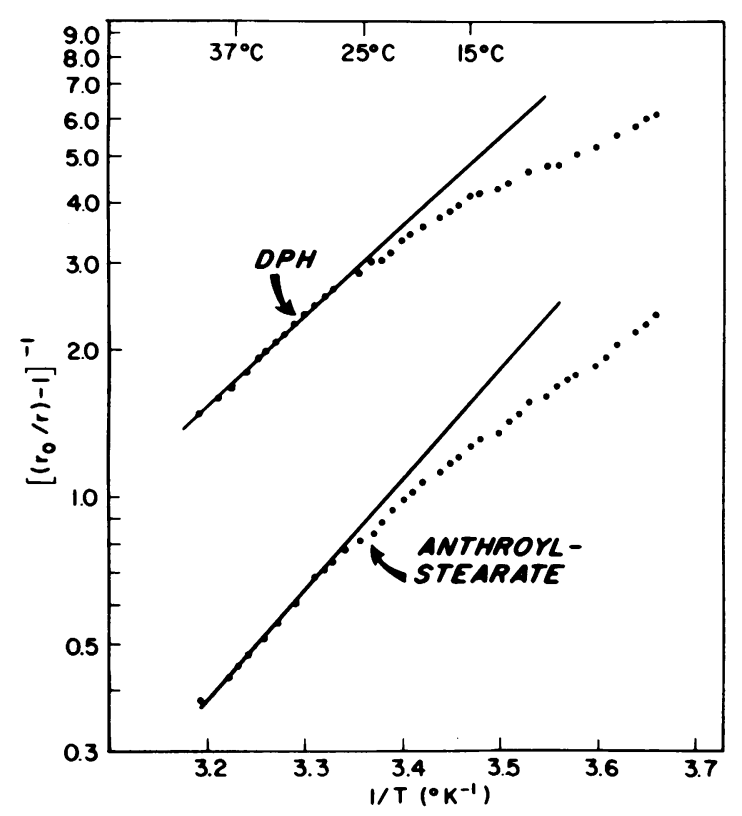

Figure 4 Temperature dependence of the fluorescence polarization of diphenylhexatriene and anthroyl-stearate in liposomes prepared from rat jejunal microvillus membrane lipid. Horizontal axis is labeled as in Fig. 2.

slope at approximately $26 \pm 2^{\circ} \mathrm{C}($ mean $\pm \mathrm{SE})$, with a tendency to curvilinear plots at the lower temperatures. Fig. 3 illustrates a representative study with jejunal microvillus membranes and liposomes prepared from them. As the temperature was lowered from $40^{\circ} \mathrm{C}$, an initial linear region of relatively high slope was followed at $30.5^{\circ} \mathrm{C}$ (membranes) or $29^{\circ} \mathrm{C}$ (liposomes) by a decrease in slope and a curvilinear plot. ${ }^{2}$ Since such changes in slope indicate the occurrence of a phase transition confirmatory evidence was sought. To determine whether the phenomenon was probe-dependent, liposomes prepared from jejunal microvillus membranes were tested with DPH or anthroyl-stearate, and the results are shown in Fig. 4. Clear evidence of a change in slope was observed with both DPH $\left(26^{\circ} \mathrm{C}\right)$ and anthroyl-stearate $\left(27^{\circ} \mathrm{C}\right)$. Moreover, a sample of jejunal microvillus membrane lipid which was hydrated and examined by differential scanning microcalorimetry in the laboratory of Dr. Donald M. Small demonstrated a phase transition at about $28^{\circ} \mathrm{C}$; the transition temperature observed in this sample by DPH fluorescence polarization was $30.5^{\circ} \mathrm{C}$.

Transition temperatures observed for all the intestinal preparations examined are listed in Table IV along with values of $\Delta \mathrm{E}$ and $\mathrm{A}$ (Methods) determined from the initial, linear regions of the plots. The mean transition temperature $( \pm \mathrm{SE})$ of the microvillus mem-

\footnotetext{
${ }^{2}$ In each temperature study a plot of $\log \bar{\eta}$ (calculated as described in Methods) against $1 / \mathrm{T}$ was also made. The phase transition indicated by a change in slope was somewhat accentuated in this plot as compared to Figs. 3-4, but the temperature of the phase transition was identical and the general shape of the plots was quite similar to those illustrated. The data in Table IV are derived solely from plots of $\log \bar{\eta}$ vs. 1/T.
}

TABLE IV

Parameters Determined from Temperature Studies of the Fluorescence Polarization of Diphenylhexatriene

\begin{tabular}{lcccc}
\hline \multicolumn{1}{c}{ Preparation } & $\begin{array}{c}\text { No. of } \\
\text { preparations }\end{array}$ & $\Delta \mathrm{E}$ & $\mathrm{A}$ & $\begin{array}{c}\text { Transition } \\
\text { temperature }\end{array}$ \\
& & $k c a l / m o l$ & $\mu P o i s e$ & ${ }^{\circ} \mathrm{C}$ \\
Microvillus membranes: & & & & \\
$\quad$ Duodenal & 2 & $10.0,8.4$ & & 21,22 \\
$\quad$ Jejunal & 4 & $10.0 \pm 0.7$ & & $26 \pm 2$ \\
$\quad$ Ileal & 2 & $8.6,11.3$ & & 28,34 \\
All segments & 8 & $9.8 \pm 0.5$ & $3 \pm 1$ & $26 \pm 2$ \\
Liposomes, jejunal microvillus & 2 & $10.1,11.1$ & $0.4,0.1$ & 28,29 \\
$\quad$ membranes & 12 & $8.3 \pm 0.5$ & $16 \pm 12$ & $23 \pm 1$ \\
Whole brush borders & 5 & $9.5 \pm 0.5$ & $0.2 \pm 0.04$ & $23 \pm 2$ \\
Liposomes, brush borders & 2 & $8.4,9.0$ & 8,20 & - \\
Erythrocyte ghost membranes & 1 & 9.2 & 1 & - \\
Liposomes, erythrocyte ghost & & & &
\end{tabular}

Values are means $\pm S E$ or individual values. The parameters $\Delta E$ and $A$ were determined from plots of $\log \bar{\eta}$ vs. $1 / T$, as described in the text (Eq. 2) and in a prior report (3). For the intestinal preparations the $\Delta \mathrm{E}$ and $\mathrm{A}$ values are determined for the initial, linear slope of the plot in the temperature range from $40^{\circ} \mathrm{C}$ to the transition temperature. 


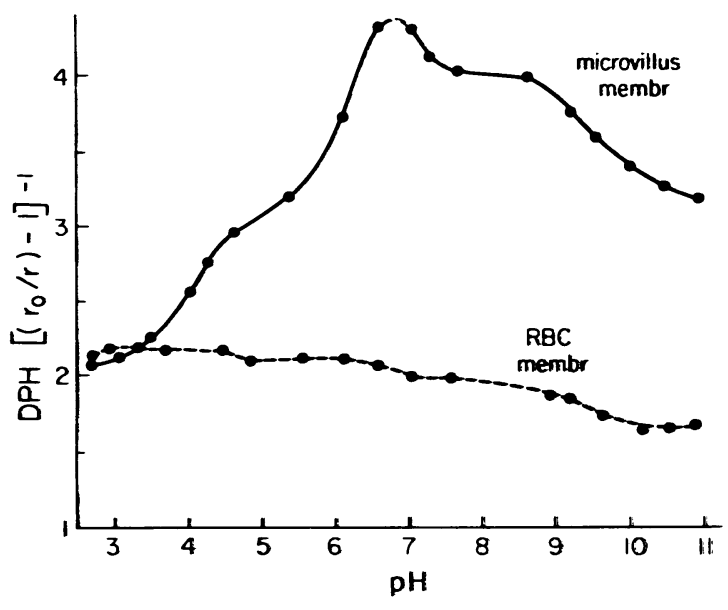

FIGURE 5 Effects of $\mathrm{pH}$ on the fluorescence polarization of diphenylhexatriene in rat jejunal microvillus membranes and in human erythrocyte ghost membranes (RBC membr).

branes, $26 \pm 2^{\circ} \mathrm{C}$, and of the liposomes, $28-29^{\circ} \mathrm{C}$, was the same within experimental error. Similarly, an identical value, $23^{\circ} \mathrm{C}$, was observed for the brushborder transition temperature and that of their liposomes. The transition temperature, therefore, is not influenced by the membrane proteins. A similar conclusion obtains for the $\Delta \mathbf{E}$ values. As shown in Table IV, the $\Delta E$ values of the microvillus membranes and their liposomes are the same within experimental error; the corresponding erythrocyte membrane and liposome values are also similar. In these membrane types the $\Delta \mathrm{E}$ is not significantly affected by the membrane proteins. In the microvillus membranes, however, the DPH $\left[\left(r_{o} / r\right)-1\right]^{-1}$ or $\bar{\eta}$ values are clearly greater than in the liposomes (Table III) so that an effect of the membrane proteins on the A constant would be anticipated from the relation given in equation (2). The data in Table IV indicate that the mean value of $\mathrm{A}$ of microvillus membranes and brush borders is significantly greater than that of the lipror somes $(P<0.02)$.

$p H$ studies. The effects of ambient $\mathrm{pH}$ on the fluorescence polarization of DPH in jejunal microxillius membranes as compared to erythrocyte ghost membranes are illustrated in Fig. 5. Relatively little change in the erythrocyte membrane values was observed in the $\mathrm{pH}$ range $3-11$. In contrast, marked effects were noted with the microvillus membranes. A maximal $\left[\left(r_{0} / r\right)-1\right]^{-1}$ value was observed at $\mathrm{pH} 6.5-7.0$ with decreases on both the acid and alkaline sides. In the acid range the fall was relatively steep, decreasing by over $50 \%$ to $\mathrm{pH} \mathrm{3}$, and characterized by two inflection points at approximately $\mathrm{pH} 4$ and 6 . The less: marked fall on the alkaline side also showed inflection: points.

To assess the relative contributions of membrane protein and lipid to the $\mathrm{pH}$ changes noted above, liposomes prepared from the microvillus membranes were tested similarly and the results are shown in Fig. 6 (upper curves). Change in $\mathrm{pH}$ affected the liposome $\left[\left(r_{d} / r\right)-1\right]^{-1}$ values much less than those of the membranes; a fall in $\mathrm{pH}$ from 7 to 3 decreased the liposome values only one-fourth as much as the membrane values. The general shape of the liposome curve was, however, similar to that of the membranes (Fig. 6, lower curve, expanded scale). A peak $\left[\left(r_{o} / r\right)-1\right]^{-1}$ value was observed at $\mathrm{pH}$ 6.0-6.5 with decreases on the acid and alkaline sides and inflection points at approximately pH 4 and 5.5 .

Effects of calcium. DPH, being a hydrocarbon, is relatively nonpolar as compared to anthroyl-stearate or retinol, which contain hydrophilic residues. Consequently, one would expect a difference in localization of these probes in the membrane, DPH to the more nonpolar (interior) regions and the other probes to the more polar (surface) areas. Since calcium is believed to interact with the polar head groups of

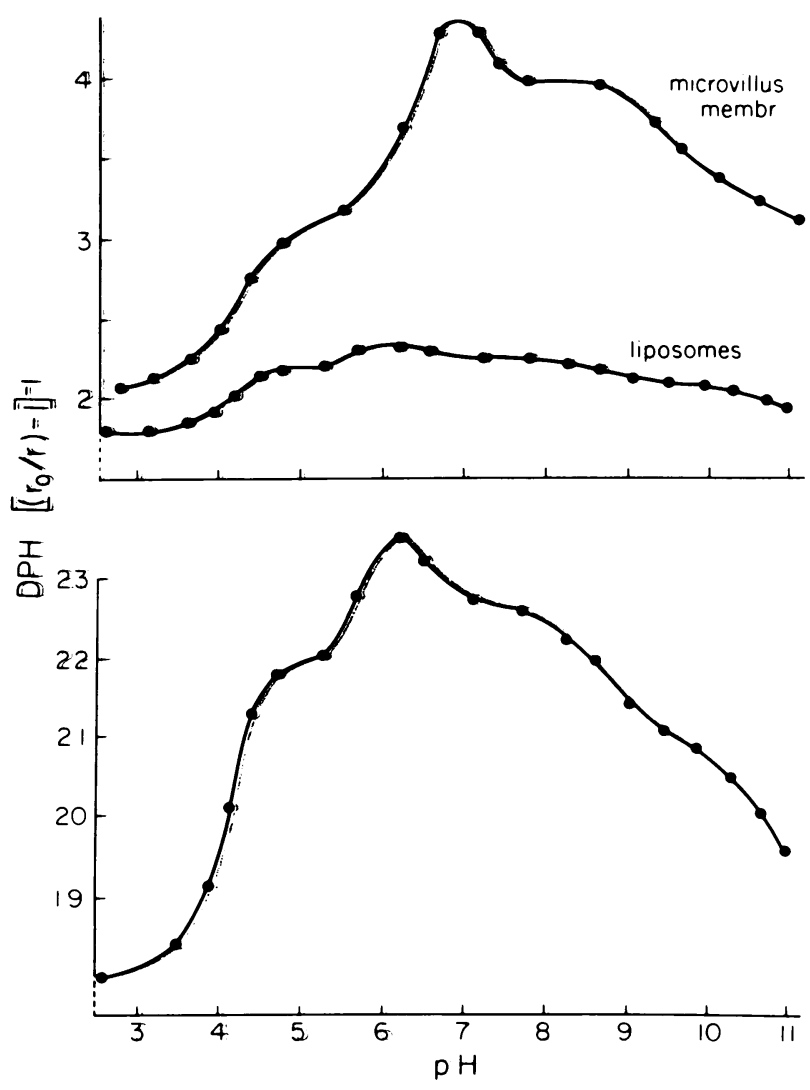

FIGURE 6 Effects of $\mathrm{pH}$ on the fluorescence polarization of diiphenylhexatriene in rat jejunal microvillus membranes and in liposomes prepared from their lipid. Upper curves: comparison of whole membranes and liposomes over the $\mathrm{pH}$ range 3-11.. Lower curve: re-plot of the same liposome values on a fivefold expanded vertical scale of $\left[\left(r_{o} / r\right)-1\right]^{-1}$.

Dynamics of Microvillus Membranes 
TABLE V

Effects of Calcium on Fluorescence Polarization of Three Probes in Microvillus Membranes

\begin{tabular}{|c|c|c|c|c|c|}
\hline \multirow[b]{2}{*}{ Probe } & \multirow[b]{2}{*}{ Segment } & \multicolumn{4}{|c|}{$\begin{array}{l}\text { Fluorescence polarization } \\
\qquad\left[\left(r_{d} d r\right)-1\right]^{-1}\end{array}$} \\
\hline & & $-\mathrm{Ca}$ & $+\mathrm{Ca}$ & $\begin{array}{l}\text { Perc } \\
\text { chan }\end{array}$ & $\begin{array}{l}\text { ent } \\
\text { nge }\end{array}$ \\
\hline \multirow{4}{*}{$\begin{array}{l}\text { Diphenyl- } \\
\text { hexatriene }\end{array}$} & Duodenum & 3.45 & 3.52 & & +2.0 \\
\hline & Jejunum & 3.66 & 3.65 & & -0.3 \\
\hline & Ileum & 3.90 & 3.82 & & -2.0 \\
\hline & & & & Mean & -0.1 \\
\hline \multirow{4}{*}{$\begin{array}{l}\text { Anthroyl- } \\
\text { stearate }\end{array}$} & Duodenum & 0.77 & 0.81 & & +5.2 \\
\hline & Jejunum & 0.80 & 0.84 & & +5.0 \\
\hline & Ileum & 0.86 & 0.93 & & +8.1 \\
\hline & & & & Mean & +6.1 \\
\hline \multirow[t]{4}{*}{ Retinol } & Duodenum & 2.09 & 2.27 & & +8.6 \\
\hline & Jejunum & 2.18 & 2.42 & & +11.0 \\
\hline & Ileum & 2.47 & 2.78 & & +12.5 \\
\hline & & & & Mea & +10.7 \\
\hline
\end{tabular}

Values are means for two separate groups of rats. Microvillus membranes suspended in $0.15 \mathrm{M} \mathrm{NaCl}-5 \mathrm{mM}$ Hepes-Tris of pH 7.5 were tested at $25^{\circ} \mathrm{C}$ in the presence or absence of $2.5 \mathrm{mM} \mathrm{CaCl}$. On paired analysis (all segments) the effects of calcium are significant for anthroyl-stearate $(\mathrm{SEM}=0.009$, $P<0.005)$ and retinol $(\mathrm{SEM}=0.039, P<0.005)$ but not for $\mathrm{DPH}$ $(\mathrm{SEM}=0.049)$.

membrane phospholipids $(32,33)$, we hypothesized that the cation might influence the fluorescence polarization of the more polar probes but not that of DPH. The hypothesis was tested with microvillus membranes from two groups of rats and the results are shown in Table V. Values of $\left[\left(r_{0} / r\right)-1\right]^{-1}$ for DPH were not affected by calcium, whereas those of anthroyl-stearate and retinol, respectively, were increased by $6.1 \%(P<0.005)$ and $10.7 \%(P<0.005)$.

\section{DISCUSSION}

The intestinal microvillus membrane is highly specialized to perform transport and enzymatic functions essential for normal digestion and absorption. In keeping with this distinctive functional specialization the fluorescence polarization studies reported here demonstrate several unique features of the dynamics of the microvillus membrane lipids. The polarization of the fluorescence of DPH in the membranes, expressed as $\left[\left(r_{0} / r\right)-1\right]^{-1}$ or as $\bar{\eta}$, the "microviscosity", is exceptionally high, indeed, the highest value yet reported in normal biological membranes. Moreover, studies of the temperature dependence of the fluorescence polarization indicate clearly the occurrence of a phase transition, the first to be demonstrated and confirmed in plasma membranes isolated directly from a mammalian organism.

Inasmuch as a number of biological membranes and cell types have now been studied with DPH, direct comparisons of the $\bar{\eta}\left(25^{\circ} \mathrm{C}\right)$ values are possible. ${ }^{3}$ Ranked in order, the membranes and their respective mean values (poise) are: rat ileal, jejunal, and duodenal microvillus membranes, 14.7, 12.5, and 12.4 (Table I); human erythrocyte ghost membranes, 6.3 (3); bovine chromaffin granules, $5.2(3)$; normal human lymphocytes, 4.4 (3); human chronic lymphatic leukemic lymphocytes, 3.4 (3); beef heart mitochondria 2.1 (3); rat liver cells, 1.7 (3); mouse 3T3d cells, 1.5 (7); and human Burkitt lymphoma cells, 1.2 (3). The $\bar{\eta}$ values of the present studies are also greater in microvillus membranes as compared to suspensions of whole brush borders, unfractionated mucosal homogenates, or whole mucosal cells examined with a fluorescence polarization microscope. Indeed, the fluorescence polarization of DPH could be used to monitor the purification of the membranes from the homogenates. Regional differentiation of the small intestinal mucosa is reflected in the higher polarization values observed for ileal as compared to more proximal segments with each of the three fluorophores, DPH (Table I), anthroyl-stearate (Table II), and retinol ([23]; Table V). The functional significance of this pattern or of the very high $\bar{\eta}$ values of the microvillus membranes generally is unknown. Two possibilities, however, are noteworthy. Recent studies $(3,34)$ suggest that high $\bar{\eta}$ values increase the availability or rotational mobility of the surface receptors of certain membranes. Since a major function of the microvillus membrane surface is to adsorb a variety of nutrients, the high $\bar{\eta}$ values may assure optimal availability of essential surface receptors or enzymes. The second possibility derives from a number of studies $(35,36)$ which demonstrate that the cholesterol content of artificial or natural membranes can influence markedly the passive permeability, carrier-mediated permeability, and electrical properties of the membranes. Since cholesterol content is closely correlated with $\bar{\eta}(3,35)$, it is reasonable to suggest that the normal transport and barrier functions of the microvillus membrane may depend on the high $\bar{\eta}$ values.

Comparison of the fluorescence polarization of DPH in liposomes and intact microvillus membranes indicates clearly that both the lipid and protein components of the membrane contribute to the high $\bar{\eta}$ (DPH) values. The lipid contribution can be considered in terms of a number of determinants which

\footnotetext{
${ }^{3}$ It is noteworthy that the excited state lifetimes, $\tau$, used in the calculation of $\bar{\eta}$ in the studies quoted are indirect estimates. The $\bar{\eta}$ values listed are therefore only approximate values subject to correction when direct estimates of $\tau$ in the various cell preparations become available.
} 
have been defined in the past decade, mainly by extensive studies of liposomes as model membranes $(3,4,10-12,35-38)$. Increases in $\bar{\eta}$ result from increases in the molar ratio of cholesterol/phospholipid $(11,37,39,40)$, the molar ratio of sphingomyelin/lecithin $(3,12)$, or the degree of saturation of the fatty acid side chains of the polar lipids (40). The cholesterol/phospholipid ratio in rat microvillus membrane lipid has been estimated as 1.26 (25), in excess of the ratio in human erythrocyte membranes, $0.9-0.95(41)$, or in the other membrane types listed above. Furthermore, the molar ratios of sphingomyelin/ lecithin estimated in our laboratory in samples of rat jejunal microvillus membrane lipid from two groups of rats were 0.71 and 1.10 . These ratios are comparable to those of human erythrocyte membranes, 0.82 0.96 (41). Thus, the available analytical data would predict that liposomes of microvillus membrane lipid would have $\bar{\eta}(\mathrm{DPH})$ values at least as high as those of liposomes of erythrocyte membrane lipid and therefore higher than the values of the other membrane types above (3). As demonstrated in Table III, the fluorescence polarization of DPH is, in fact, similar in the intestinal and erythrocyte liposomes. On the other hand, the $\bar{\eta}$ (DPH) values of the microvillus and erythrocyte intact membranes differ markedly. In erythrocytes the values of the membranes and their liposomes are about the same (Table III), as previously reported $(2,3)$. In contrast, the microvillus membrane values are considerably higher than those of their liposomes. The presence of the membrane proteins, therefore, accounts for the exceptionally high $\bar{\eta}$ (DPH), in excess of that in erythrocyte membranes, characteristic of microvillus membranes. The studies of $\mathrm{pH}$ dependence further support this conclusion. On lowering the ambient $\mathrm{pH}$ from 7 to 3 (Fig. 5), the relatively high DPH fluorescence polarization of the microvillus membranes falls to the level of the erythrocyte membranes, and this marked decrease is for the most part absent in the liposome studies (Fig. 6), i.e., it depends upon the membrane proteins.

The effect of membrane proteins on $\bar{\eta}$ would presumably result from protein-lipid and protein-protein interactions. Although the nature of these interactions depends mainly on the particular molecules involved, the number of interactions may well relate to the total protein content of the membrane. It bears emphasis that the microvillus membrane contains a high proportion of protein/lipid, 1.7/1.0 (wt/wt) as compared for example, to the erythrocyte membrane, $1.2 / 1.0$. Thus, it is reasonable to suggest that the protein/lipid ratio of a membrane may be an additional determinant of its $\bar{\eta}$ value.

In microvillus membranes and in liposomes prepared from their lipid the $\log \bar{\eta}(\mathrm{DPH})$ varies linearly with $1 /{ }^{\circ} \mathrm{K}$ in the temperature range from 40 to $26 \pm 2^{\circ} \mathrm{C}$, i.e., in the liquid crystalline phase preceding the transition to a crystalline gel. The slope of this line represents a flow activation energy $\triangle \mathrm{E}$ (DPH), which is an index of the degree of order in the hydrophobic regions of the membrane (3). The $\triangle \mathrm{E}(\mathrm{DPH})$ values observed for microvillus membranes and erythrocyte membranes (Table IV) are approximately the same, in agreement with prior observations that the range of these values is relatively narrow in biological membranes. Since membranes with low molar ratios of cholesterol/phospholipid, e.g., beef heart mitochondrial membranes, gave $\Delta \mathrm{E}$ values considerably less than those predicted from their lipid composition, the conclusion was drawn (3) that membrane proteins lower the $\Delta \mathrm{E}$ values. It seems clear from the present results, on the other hand, that the proteins do not influence appreciably the $\Delta \mathrm{E}$ values in membranes with high cholesterol/phospholipid ratios. As shown in Table IV the $\Delta \mathrm{E}$ values of either the microvillus membranes or the erythrocyte ghost membranes are the same within experimental error as those of their corresponding liposomes.

The temperature dependence of DPH fluorescence polarization also provides clear evidence of a phase transition at $26 \pm 2^{\circ} \mathrm{C}$ in microvillus membranes and in the liposomes prepared from them. The sensitivity and validity of this fluorescence method for identification of such transitions has been amply established by studies with artificial liposome systems (3, 12-14). Since prior examination of a number of cell types and isolated membranes, including erythrocyte ghost membranes, revealed no phase transitions by similar fluorescence polarization studies $(2,3)$, the present results were confirmed by experiments with another fluorescent probe, anthroyl-stearate, and more directly by differential scanning microcalorimetry of microvillus membrane lipid. The membrane proteins seem to have no influence on the transition observed, inasmuch as the transition temperatures (Table IV) for individual microvillus membrane samples are the same within $1-2^{\circ} \mathrm{C}$ as those of the corresponding liposomes. ${ }^{4}$ The biochemical basis of the phase transition in terms

\footnotetext{
${ }^{4}$ That the membrane proteins do not appear to affect the thermal transition temperature may seem surprising in view of their proposed role in increasing the apparent microviscosity of the microvillus membrane lipids. It is noteworthy, however, that electron spin resonance studies indicate that membrane lipids consist of bulk and boundary lipids. Bulk lipids, which are relatively free of the influence of the membrane proteins and show greater fluidity, would be involved in the cooperative interaction underlying a thermal phase transition. Hence, the membrane proteins need not influence the thermal transition. On the other hand, boundary lipids, which interact relatively strongly with the membrane proteins and show reduced fluidity, would be expected to contribute to the fluorescence polarization values observed for DPH in the whole membrane and therefore to the relatively high apparent microviscosity.
} 
of specific lipid determinants is unknown as yet. Since artificial liposomes with high sphingomyelin/ lecithin ratios show phase transitions at $28-34^{\circ} \mathrm{C}$ $(3,12)$, the ratio of these substances in two samples of jejunal microvillus lipid was determined. As mentioned above, the values are similar to those in human erythrocyte ghost membranes and fail, therefore, to provide an adequate explanation. It is conceivable that the microvillus and erythrocyte membrane lipids behave differently due to a difference in the ratio of cholesterol/total polar lipid. This ratio is lower in microvillus membrane lipid due to its high content of glycolipid (25). Moreover, it has been reported (42) that erythrocyte membrane lipid, which does not show a phase transition on differential scanning calorimetry, will show a broad transition encompassing $37^{\circ} \mathrm{C}$ after removal of the cholesterol. Further studies with isolated fractions of microvillus membrane lipids, including particularly the glycolipids (25), may lead to the identification of the specific determinants of the phase transition.

An extensive literature now exists on the identification and characterization of phase transitions in model bilayers and microbial organisms (43). In addition to fluorescent probe analysis the techniques used include differential scanning calorimetry (44), X-ray diffraction (45), electron spin resonance (46-48), nuclear magnetic resonance $(49,50)$, and the temperature dependence of various enzyme and transport functions $(43,51)$. Evidence for phase transitions in mammalian membranes, however, has been limited to mouse LH cells cultured in monolayers $(52,53)$ and studied by electron spin resonance and the nitroxide spin label, $5 \mathrm{~N} 10$, in association with a number of physiological parameters. The present study provides the first clear demonstration of a phase transition in plasma membranes isolated directly from a normal mammalian tissue. While the mean transition temperature of approximately $26^{\circ} \mathrm{C}$ is sufficiently below $37^{\circ} \mathrm{C}$ to preclude a physiological role for the change in state, the transition phenomenon should prove useful in further studies of membrane transport and enzyme reactions as it has in other cell types (43, $52,53)$.

It is instructive to contrast the fluorescence polarization results obtained with the synthetic hydrocarbon, $\mathrm{DPH}$, and the essential nutrient, retinol. Prior publications $(3,12-14)$ and the present data support the hypothesis that DPH reports mainly, if not entirely, from the nonpolar lipid regions of the plasma membrane. In our studies the microvillus membranes gave values similar to the liposomes for both the $\Delta \mathrm{E}(\mathrm{DPH})$ parameter and the transition temperature. Moreover, the phase transition identified initially by DPH fluorescence polarization in the membranes was confirmed subsequently by direct microcalorimetric examination of the isolated membrane lipid. Finally, $\mathrm{Ca}^{++}$did not appreciably affect the DPH fluorescence polarization in microvillus membranes (Table V), apparently because the probe is located sufficiently far from the polar head groups of the lipids. In contrast to DPH, at least a portion of the fluorescence of retinol seems to originate from binding of vitamin A to one or more membrane proteins. As reported previously (23), treatment of microvillus membranes with trypsin decreases the fluorescence polarization and fluorescence intensity of the retinol but not those of the DPH. In the present experiments (Table III) retinol $\left[\left(r_{0} / r\right)-1\right]^{-1}$ and fluorescence intensity per milligram protein were considerably greater in a Tritonsolubilized membrane protein solution than in the intact microvillus membrane. The evidence suggests that the microvillus membrane may contain one or more binding proteins which could play a role in the absorptive mechanism for the vitamin.

Variations in ambient $\mathrm{pH}$ affected markedly the DPH fluorescence polarization in microvillus membranes, primarily by influencing the membrane proteins. The inflection points observed (Fig. 5) suggest that the side chains of glutamic acid $(\mathrm{pK} 4.1)$ and histidine $(\mathrm{pK}$ 6.1) might be involved in these effects. Aside from the significance for the molecular organization of the membrane, the change in "microviscosity" with pH is of interest because the microvillus membrane is the interface normally in contact with intralumenal $\mathrm{H}^{+}$. A speculative but intriguing possibility is that the decrease in $\bar{\eta}(\mathrm{DPH})$ at acid $\mathrm{pH}$ may represent an early stage in the destabilization of the membrane which leads eventually to mucosal cell destruction and peptic ulceration.

\section{ACKNOWLEDGMENTS}

We are very grateful to Dr. Donald M. Small for the opportunity to study microvillus membrane lipid by differential scanning microcalorimetry and to Dr. Michael Inbar and Elscint, Ltd., Haifa, Israel, for studies with a prototype fluorescence polarization microscope. We also acknowledge with gratitude the inspiration of Dr. David Nachmansohn, who initiated our collaboration via a visiting scientist program supported by the Sloan Foundation.

This work was supported by the United States-Israel Binational Science Foundation (grant no. 607), Jerusalem, Israel, the National Institutes of Health (grants AM-01483 and HL-16851), and the Irma T. Hirschl Trust.

\section{REFERENCES}

1. Shinitzky, M., and M. Inbar. 1974. Difference in microviscosity induced by different cholesterol levels in the surface membrane lipid layer of normal lymphocytes and malignant lymphoma cells. J. Mol. Biol. 85: 603615.

2. Aloni, B., M. Shinitzky, and A. Livne. 1974. Dynamics of erythrocyte lipids in intact cells, in ghost membranes 
and in liposomes. Biochim. Biophys. Acta. 348: 438441.

3. Shinitzky, M., and M. Inbar. 1976. Microviscosity parameters and protein mobility in biological membranes. Biochim. Biophys. Acta. 433: 133-149.

4. Vanderkooi, J., S. Fischkoff, B. Chance, and R. A. Cooper. 1974. Fluorescent probe analysis of the lipid architecture of natural and experimental cholesterol-rich membranes. Biochemistry. 13: 1589-1595.

5. Helgerson, S. L., W. A. Cramer, J. M. Harris, and F. E. Lytle. 1974. Evidence for a microviscosity increase in Escherichia coli cell envelope caused by colicin E 1 . Biochemistry. 13: 3057-3061.

6. Schuldiner, S., G. K. Kerwar, H. R. Kaback, and R. Weil. 1975. Energy-dependent binding of dansylgalactosides to the $\beta$-galactoside carrier protein. J. Biol. Chem. 250: $1361-1370$.

7. Fuchs, P., A. Parola, P. W. Robbins, and E. R. Blout. 1975. Fluorescence polarization and viscosities of membrane lipids of 3T3 cells. Proc. Natl. Acad. Sci. U. S. A. 72: 3351-3354.

8. Arndt-Jovin, D. J., W. Ostertag, H. Eisen, F. Klimek, and T. M. Jovin. 1976. Studies of cellular differentiation by automated cell separation. Two model systems: Friend virus-transformed cells and Hydra attenuata. J. Histochem. Cytochem. 24: 332-347.

9. Weber, G. 1953. Rotational Brownian motion and polarization of the fluorescence of solutions. Adv. Protein Chem. 8: 415-459.

10. Shinitzky, M., A-C. Dianoux, C. Gitler, and G. Weber. 1971. Microviscosity and order in the hydrocarbon region of micelles and membranes determined with fluorescent probes. I. Synthetic micelles. Biochemistry. 10: 21062113.

11. Cogan, U., M. Shinitzky, G. Weber, and T. Nishida. 1973. Microviscosity and order in the hydrocarbon region of phospholipid and phospholipid-cholesterol dispersions determined with fluorescent probes. Biochemistry. 12: 521-528.

12. Shinitzky, M., and Y. Barenholz. 1974. Dynamics of the hydrocarbon layer in liposomes of lecithin and sphingomyelin containing dicetylphosphate. J. Biol. Chem. 249: 2652-2657.

13. Andrich, M. P., and J. M. Vanderkooi. 1976. Temperature dependence of 1,6-diphenyl-1,3,5-hexatriene fluorescence in phospholipid artificial membranes. Biochemistry. 15: 1257-1261.

14. Jacobson, K., and D. Papahadjopoulos. 1975. Phase transitions and phase separations in phospholipid membranes induced by changes in temperature, $\mathrm{pH}$, and concentration of bivalent cations. Biochemistry. 14: $152-161$.

15. Shinitzky, M. 1974. Fluidity and order in the hydrocarbon-water interface of synthetic and biological micelles as determined by fluorescence polarization. Isr. J. Chem. 12: 879-890.

16. Forstner, G. G., S. M. Sabesin, and K. J. Isselbacher. 1968. Rat intestinal microvillus membranes. Purification and biochemical characterization. Biochem. J. 106: $381-390$.

17. Kowarski, S., and D. Schachter. 1973. Vitamin D and adenosine triphosphatase dependent on divalent cations in rat intestinal mucosa. J. Clin. Invest. 52: 27652773.

18. Hopfer, U., K. Nelson, J. Perrotto, and K. J. Isselbacher. 1973. Glucose transport in isolated brush border from rat small intestine. J. Biol. Chem. 248: 25-32.

19. Schmitz, J., H. Preiser, D. Maestracci, B. K. Ghosh,
J. J. Cerda, and R. K. Crane. 1973. Purification of the human intestinal brush border membrane. Biochim. Biophys. Acta. 323: 98-112.

20. Dulbecco, R., and M. Vogt. 1954. Plaque formation and isolation of pure lines with poliomyelitis viruses. J. Exp. Med. 99: 167-182.

21. Dodge, J. T., C. Mitchell, and D. J. Hanahan. 1963. The preparation and chemical characteristics of hemoglobin-free ghosts of human erythrocytes. Arch. Biochem. Biophys. 100: 119-130.

22. Lowry, O. H., N. J. Rosebrough, A. L. Farr, and R. J. Randall. 1951. Protein measurement with the Folin phenol reagent. J. Biol. Chem. 193: 265-275.

23. Schachter, D., U. Cogan, and M. Shinitzky. 1976. Interaction of retinol and intestinal microvillus membranes studied by fluorescence polarization. Biochim. Biophys. Acta. 448: 620-624.

24. Folch, J., M. Lees, and G. H. Sloane-Stanley. 1957. A simple method for the isolation and purification of total lipides from animal tissues. J. Biol. Chem. 226: 497-509.

25. Forstner, G. G., K. Tanaka, and K. J. Isselbacher. 1968. Lipid composition of the isolated rat intestinal microvillus membrane. Biochem. J. 109: 51-59.

26. Rosenberg, S. A., and G. Guidotti. 1968. The protein of human erythrocyte membranes. I. Preparation, solubilization, and partial characterization. J. Biol. Chem. 243: 1985-1992.

27. Yavin, E., Z. Yavin, and J. H. Menkes. 1975. Polyunsaturated fatty acid metabolism in neuroblastoma cells in culture. J. Neurochem. 24: 71-77.

28. Bartlett, G. R. 1959. Phosphorus assay in column chromatography. J. Biol. Chem. 234: 466-468.

29. Batt, E. R., and D. Schachter. 1973. Transport of monosaccharides. I. Asymmetry in the human erythrocyte mechanism. J. Clin. Invest. 52: 1686-1697.

30. Kanai, M., A. Raz, and D. S. Goodman. 1968. Retinolbinding protein: the transport protein for vitamin $\mathrm{A}$ in human plasma. J. Clin. Invest. 47: 2025-2043.

31. Cogan, U., M. Kopelman, S. Mokady, and M. Shinitzky. 1976. Binding affinities of retinol and related compounds to retinol binding proteins. Eur. J. Biochem. 65: 71-78.

32. Shah, D. O., and J. H. Schulman. 1967. The ionic structure of lecithin monolayers. J. Lipid Res. 8: 227-233.

33. Papahadjopoulos, D. 1968. Surface properties of acidic phospholipids: interaction of monolayers and hydrated liquid crystals with uni- and bi-valent metal ions. Biochim. Biophys. Acta. 163: 240-254.

34. Shattil, S. J., R. Anaya-Garlindo, J. Bennett, R. W. Colman, and R. A. Cooper. 1975. Platelet hypersensitivity induced by cholesterol incorporation. J. Clin. Invest. 55: 636-643.

35. Papahadjopoulos, D., M. Cowden, and H. Kimelberg. 1973. Role of cholesterol in membranes. Effects on phospholipid-protein interactions, membrane permeability and enzymatic activity. Biochim. Biophys. Acta. 330: $8-26$.

36. Wiley, J. S., and R. A. Cooper. 1975. Inhibition of cation cotransport by cholesterol enrichment of human red cell membranes. Biochim. Biophys. Acta. 413: 425-431.

37. Hubbell, W. L., and H. M. McConnell. 1971. Molecular motion in spin-labelled phospholipids and membranes. J. Am. Chem. Soc. 93: 314-326.

38. Bangham, A. D. 1972. Lipid bilayers and biomembranes. Ann. Rev. Biochem. 41: 753-776.

39. Chapman, D., and S. A. Penkett. 1966. Nuclear magnetic resonance spectroscopic studies of the interaction of phospholipids with cholesterol. Nature (Lond.). 211: 1304-1305. 
40. Oldfield, E., and D. Chapman. 1971. Effect of cholesterol and cholesterol derivatives on hydrocarbon chain mobility in lipids. Biochem. Biophys. Res. Commun. 43: 610-616.

41. Van Deenen, L. L. M., and J. De Gier. 1974. Lipids of the red cell membrane. In The Red Blood Cell. D. MacN. Surgenor, editor. Academic Press, Inc., New York. 2nd edition, 1: 147-211.

42. Chapman, D. 1973. Some recent studies of lipids, lipidcholesterol and membrane systems. In Biological Membranes. D. Chapman and D. F. H. Wallach, editors. Academic Press, Inc., New York. 2: 91-140.

43. Fox, C. F. 1975. Phase transitions in model systems and membranes. In Biochemistry of Cell Walls and Membranes. C. F. Fox, editor. University Park Press, Baltimore, Md. 2: 279-306.

44. Ladbrooke, B. D., R. M. Williams, and D. Chapman. 1968. Studies on lecithin-cholesterol-water interactions by differential scanning calorimetry and X-ray diffraction. Biochim. Biophys. Acta. 150: 333-340.

45. Luzzati, V., T. Gulik-Krzywicki, and A. Tardieu. 1968. Polymorphism of lecithins. Nature (Lond.). 218: 10311034.

46. Hubbell, W. L., and H. M. McConnell. 1968. Spinlabel studies of the excitable membranes of nerve and muscle. Proc. Natl. Acad. Sci. U. S. A. 61: 12-16.

47. Scandella, C. J., P. Devaux, and H. M. McConnell.
1972. Rapid lateral diffusion of phospholipids in rabbit sarcoplasmic reticulum. Proc. Natl. Acad. Sci. U. S. A. 69: 2056-2060.

48. Caron, F., L. Mateu, P. Rigney, and R. Azerad. 1974. Chain motions in lipid-water and protein-lipid-water phases: a spin-label and X-ray diffraction study. J. Mol. Biol. 85: 279-300.

49. Sheetz, M. P., and S. I. Chan. 1972. Effect of sonication on the structure of lecithin bilayers. Biochemistry. 11: 4573-4581.

50. Horwitz, A. F., M. P. Klein, D. M. Michaelson, and S. J. Cohler. 1973. Magnetic resonance studies of membrane and model membrane systems. V. Comparison of aqueous dispersions of pure and mixed phospholipids. Ann. N. Y. Acad. Sci. 222: 468-488.

51. Raison, J. K. 1973. Temperature-induced phase changes in membrane lipids and their influence on metabolic regulation. Symp. Soc. Exp. Biol. 27: 485-512.

52. Wisnieski, B. J., J. G. Parkes, Y. O. Huang, and C. F. Fox. 1974. Physical and physiological evidence for two phase transitions in cytoplasmic membranes of animal cells. Proc. Natl. Acad. Sci. U. S. A. 71: 4381-4385.

53. Wisnieski, B. J., Y. O. Huang, and C. F. Fox. 1974. Physical properties of the lipid phase of membranes from cultured animal cells. J. Supramol. Struct. 2: $593-608$. 